\title{
Influence of different kinds of steel fibers on flexural behavior of ultra-high performance concrete beam by ANSYS
}

\author{
Mingyue Chen ${ }^{1}$ and Changchun Pei ${ }^{1, a,{ }^{*}}$ \\ ${ }^{1}$ Department of Structural Engineering,College of Engineering,YanbianUniversity, Yanji, 133002, \\ China; \\ ${ }^{a, *}$ Corresponding author: peicc@ybu.edu.cn
}

\begin{abstract}
Keywords: ultra-high performance; steel fiber reinforced concrete; mid-span moment; ultimate bearing
\end{abstract} capacity; finite element analysis.

\begin{abstract}
In this paper, an ANSYS finite element simulation analysis was conducted to study the influences of different types of steel fibers on the ultra-high performance concrete beams in the initial cracking state and yield state of bending performance. The results indicate that the incorporation of steel fiber can improve the mid-span moment and stress in the initial crack state and yielded state and prevent the concrete from cracking, thereby improving the flexural behavior of the beam. The higher the tensile strength of the fiber, the more obvious the improvement effect is. In this paper, the end hook type fiber with the tensile strength of $1100 \mathrm{MPa}$ exhibits the best enhancement effect. The formula of ultimate flexural capacity for UHPC beam is deduced.
\end{abstract}

\section{Introduction}

With the development of the construction industry, concrete used in the structure has gradually tends to ultra-high performance. Since Larrard[1] put forward the concept of super high performance concrete (UHPC) for the first time in 1994, UHPC has been studied at home and abroad accompanied by a series of research results have been obtained. Since 2002, Lin Xiaosong[2], Cao Xiaoxia[3], Giuseppe Tiberti[4] and Jacek Katzer[5] studied the effect of size and type of steel fibers on the mechanical properties of concrete. The effect of fiber incorporation on compressive and tensile strength of SFRC was studied by Yang Jiujun[6], Du Xiuli[7] and Serkan Tokgoz et al[8]. But most is the material performance study of concrete UHPC, there are little research on structural properties.

Therefore, in order to enhance the flexural performance of concrete beams in this paper, the effect of different types of steel fibers on the mid-span bending moment and deflection of UHPC beams under initial cracking and yield conditions is analyzed through the ANSYS finite element simulation analysis, to provide theoretical reference for future research on flexural behavior of UHPC beams.

\section{Materials and design}

In this paper, using the non-steel fiber reinforced UHPC concrete beam as the reference beam to be mixed with 6 different types fiber, a total of seven beams are designed. Water-cement ratio is 0.18 , beam length are $1800 \mathrm{~mm}$, the net span is $1500 \mathrm{~mm}$, and beam section size are $150 \mathrm{~mm} \times 250 \mathrm{~mm}$ (Fig.1). The longitudinal tensile reinforcement of the beam choose 4D22 of HRB500 steel bar with the HRB335 reinforced 2B10 compressive reinforcement, and the stirrup choose B10@100 of HRB500 steel bar, and the elastic modulus of the steel is 200GPa. The physical properties of the six different kinds of steel fibers whose content is $2.2 \%$ are shown in Table 1 . And through the ANSYS

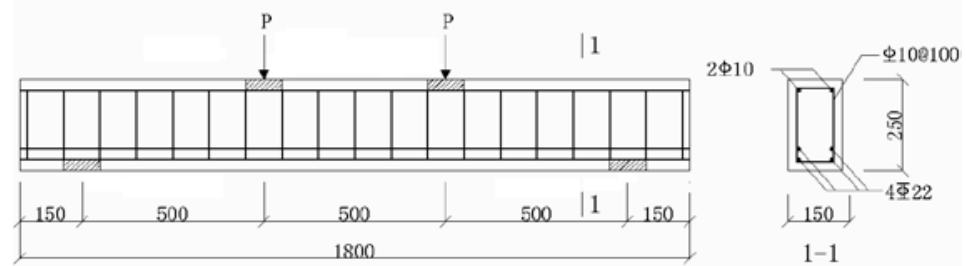

Fig. 1 The structure diagram of the UHPC beam 
Table 1 Physical properties of steel fiber

\begin{tabular}{ccccc}
\hline $\begin{array}{c}\text { SF } \\
\text { type }\end{array}$ & $\begin{array}{c}\text { Tensile } \\
\text { strength } \\
(\mathrm{MPa})\end{array}$ & $\begin{array}{c}\text { Length } \\
(\mathrm{mm})\end{array}$ & $\begin{array}{c}\text { Section } \\
(\mathrm{mm})\end{array}$ & $\begin{array}{c}\mathrm{L} / \mathrm{D} \\
\text { ratio }\end{array}$ \\
\hline B1 & 2000 & 40 & $\mathrm{~d}=1.0$ & 40.0 \\
D1 & 2000 & 30 & $\mathrm{~d}=1.0$ & 30.0 \\
B2 & 1100 & 40 & $\mathrm{~d}=0.8$ & 50.0 \\
D2 & 1100 & 35 & $\mathrm{~d}=0.9$ & 38.9 \\
B3 & 590 & 32 & $1.3 \times 1.0$ & 24.9 \\
L3 & 590 & 32 & $1.2 \times 0.9$ & 27.3 \\
\hline
\end{tabular}

Table 2 Details of Specimens

\begin{tabular}{cccccc}
\hline $\begin{array}{c}\text { Speci } \\
\text { mens }\end{array}$ & W/C & $\begin{array}{c}\text { SF } \\
\text { content } \\
(\%)\end{array}$ & $\begin{array}{c}\text { Tensile } \\
\text { bar }\end{array}$ & $\begin{array}{c}\text { Strength } \\
(\mathrm{MPa})\end{array}$ & $\begin{array}{c}\text { Young’s } \\
\text { modulus } \\
(\mathrm{GPa})\end{array}$ \\
\hline $\mathrm{S}$ & 0.18 & 2.2 & $4 \mathrm{D} 22$ & 115.29 & 46.08 \\
$\mathrm{~B} 1$ & 0.18 & 2.2 & $4 \mathrm{D} 22$ & 121.12 & 47.51 \\
$\mathrm{D} 1$ & 0.18 & 2.2 & $4 \mathrm{D} 22$ & 120.12 & 48.02 \\
$\mathrm{~B} 2$ & 0.18 & 2.2 & $4 \mathrm{D} 22$ & 120.83 & 47.63 \\
$\mathrm{D} 2$ & 0.18 & 2.2 & $4 \mathrm{D} 22$ & 127.09 & 47.05 \\
B3 & 0.18 & 2.2 & $4 \mathrm{D} 22$ & 113.21 & 47.69
\end{tabular}

finite element simulation, the initial cracking and yield state of the moment and deflection of the cross are analyzed (Table 2).

\section{The finite element model}

\subsection{Element types.}

Due to the different properties of internal materials, the concrete itself presents complex nonlinear behavior, and the reinforced concrete becomes complicated. In this paper, LINK180 bar element is used to define the physical properties of steel, at the same time SOLID65 units is used in concrete, and the reinforced concrete beam is analyzed and treated by separate model. The beam which is simply supported beam is applied third point surface uniformly distributed loading. The finite element mesh of the concrete specimen and reinforcement is shown in Fig. 2 and Fig. 3.
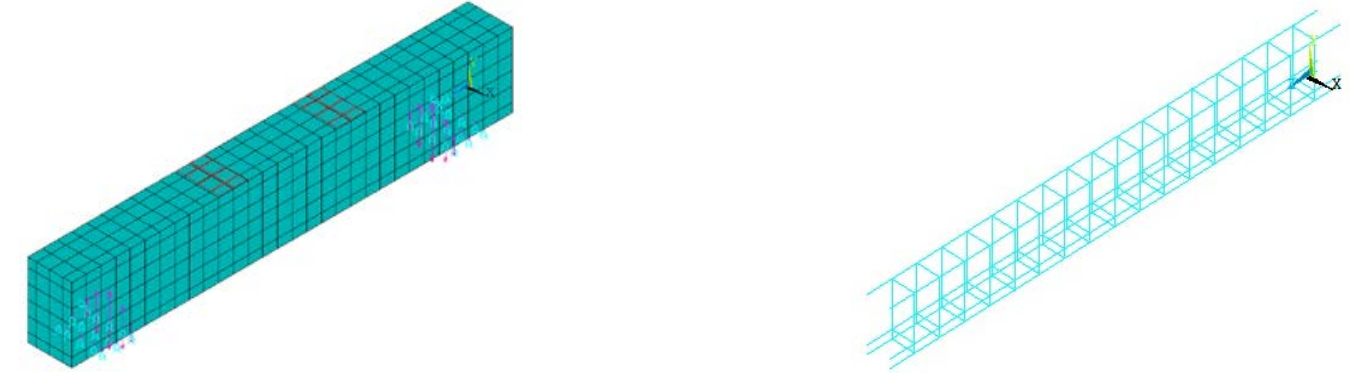

Fig.2 The finite element model of concrete beam Fig.3 The finite element model of steel

\subsection{The constitutive relation of concrete.}

Because of the few domestic researches on the constitutive relation of UHPC, the stress-strain curve equation proposed by Liu Yong-sheng[9]:

$$
\sigma=K_{\mathrm{f}} K_{\varepsilon} E(1-D) \varepsilon
$$

The $K_{\mathrm{f}}, K_{\varepsilon}, D$ is given by:

$$
\begin{gathered}
K_{f}=0.45987 \ln \left(V_{f}+0.00346\right)+3.60643 \\
\mathrm{~K}_{\varepsilon}=1.04656-0.07846 \lg \left(\frac{\varepsilon}{\varepsilon_{\mathrm{s}}}\right)+0.04619\left[\lg \left(\frac{\varepsilon}{\varepsilon_{s}}\right)\right]^{2} \\
\mathrm{D}=1-\exp \left[-\frac{\left(\varepsilon-\varepsilon^{*}\right)^{\mathrm{m}}}{\mathrm{a}}\right]
\end{gathered}
$$

Where $m$ and $a$ are the material parameter which are related to fiber volume content and strain rate; and $\varepsilon^{*}$ is the threshold strain starting from the cumulative the material damage; $\varepsilon_{S}$ references strain rate, $\varepsilon_{\mathrm{s}}=10^{-5} / \mathrm{s} ; V_{f}$ is the fiber volume content; $E$ indicates the Young's modulus of the material; $D$ is the amount of damage, $0 \leq D \leq 1$; Concrete's poisson ratio is 0.2 .

\subsection{The constitutive relation of steel.}

The corresponding parameters are determined according to GB 50010-2010 "Code for Design of Concrete Structures":

$$
\sigma_{s}= \begin{cases}E_{s} \varepsilon_{s} & \varepsilon_{s} \leq \varepsilon_{y} \\ f_{y} & \varepsilon_{s}>\varepsilon_{y}\end{cases}
$$


Where $E_{s}$ is elastic modulus of steel; $\varepsilon_{s}$ is the yield strain of steel; $f_{y}$ is the yield stress of steel; Steel's poisson ratio is 0.3 .

\subsection{Constitutive model of material.}

Before the crushing of concrete, the above constitutive relation was used to simulate, and the crushing was followed by the William-Warnke five-parameter failure criterion. In the parameter design, the shear stress transmission coefficient of open crack is 0.5 , the shear stress transmission coefficient of closed crack is 0.95, In this paper ANSYS simulation only consider the uniaxial compressive strength of -1 , crushing off the function, the remaining parameters for the default value. Load the number of sub-steps to consider the computer computing power and convergence as 60 , to avoid divergence. The maximum number of iterations is 20 .

\section{Finite element simulation results and analysis}

\subsection{Initial cracking state.}

\subsubsection{The initial crack midspan moment and deflection.}

Fig. 4 shows the bending moment and deflection diagram on the initial cracking state of different types of steel fiber concrete beams. From Fig. 4(a), it can be seen that although the bending moment of the beams is increased to different extent compared with the reference specimen $S$ after incorporating different types of steel fiber, but the variation range is not big. The reason is, in this paper ANSYS analysis, load the number of substeps are same, so that the initial cracking load is basically same. And the incorporation of fiber increase the tensile properties of the protective layer of concrete beams, so that the bending moment of the beam in the mid-crack also increased. In contrast to $\mathrm{S}$, the bending moment of $\mathrm{B} 1$ is increased by $15.76 \%$ which is the most obvious enhancement effect, mainly because of, the initial cracking stage, fiber and concrete matrix as a whole bear load, and B1 fiber is corrugated fiber between which with concrete matrix the a large cohesive force exist, to prevent concrete protective layer from cracking. The bending moments of the beams D2, B3 and B2 are increased by $8.7 \%, 3.19 \%$ and $2.61 \%$, respectively.

As shown in Fig. 4(b), with respect to the reference specimen $S$, the addition of the different types of steel fibers resulted in a decrease of the mid-span deflection of the other specimens except the B1 beam. That is, the initial deflection of beam B1 is $8 \%$ higher than the base beam $\mathrm{S}$, which is due to the cracking load of B1 beam is slightly larger than that of other beams, the deflection as well. Then the cracking deflection of beams B3, D2, B2, L3, D1 are reduced by $5 \%, 26.46 \%, 31.36 \%$, $32.6 \%$ and $33.61 \%$, respectively.

\subsubsection{Equivalent crack stress cloud pattern.}

Fig. 5 shows the equivalent crack stress of different types UHPC beams. It can be seen from the figure that the maximum cracked compressive stress occurs in the bearing during the initial cracking stage, mainly because the surface constraint at bearing place leads to stress concentration and easily cracking. With the incorporation of

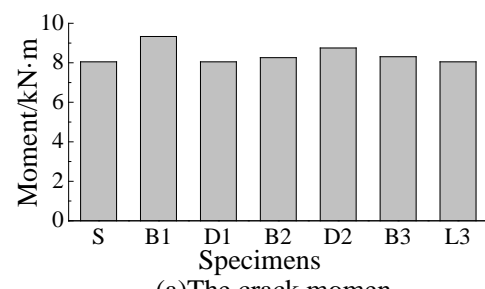

(a)The crack momen

Fig. 4 The initial crack midspan moment and deflection

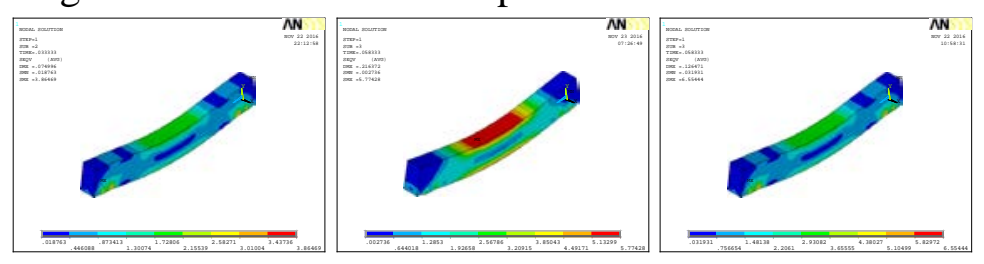

(a)S

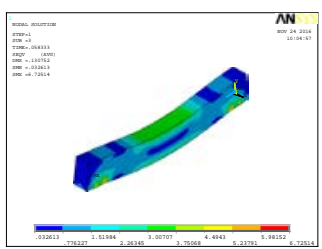

(d)B2

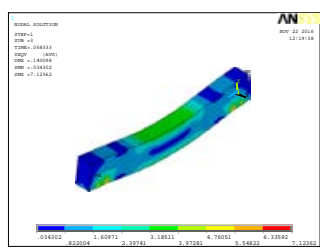

(e)D2 (b)B1 (c)D1

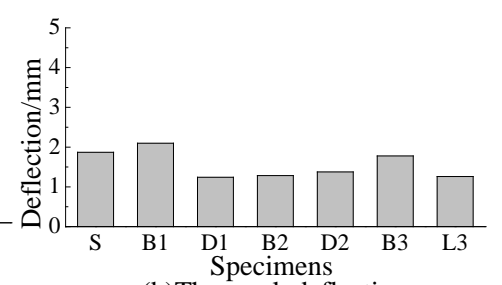

(b)The crack deflection

(c) 1

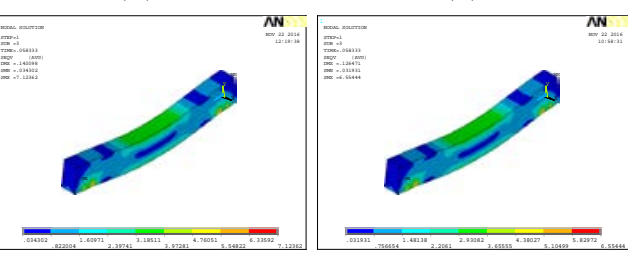

(f)B3

(g)L3

Fig. 5 The Equivalent cracking on Mises stress of UHPC beam 
different types of steel fibers, the maximum the cracking stress of beam are increased, that is, compared with the reference beam S increased by $30 \%$ to $45 \%$. Mainly due to the steel fiber incorporation, the concrete matrix and fiber as a whole load, and steel fiber grappling the concrete matrix, restrict the crack development, significantly increase the initial cracking stress. Among all the components the B1 beam has the most obvious enhancement effect, because the B1 fiber itself has larger tensile strength value and L/D ratio, and the cementation with cement base makes the reinforcing effect of the steel fiber giving full play.

\subsection{Component yield state}

\subsubsection{The mid-span bending moment and deflection in the yield condition.}

Fig. 6 shows the bending moment and deflection of UHPC beam in the yield state. As shown in Fig. 6(a), in the yield state, the bending moment of the beams D2 and D1 is 3.56\% and 3.08\% higher than that of the reference beam S, respectively, followed by beams B2, B1 increase $2.37 \%, 1.97 \%$. The results show that the increase of the hook fiber incorporation is slightly larger than that of the corrugated fiber, for the end hooks at both ends of the end hook fiber enhance the anchoring performance between the steel fiber and the concrete. The fibers with the same strength have the strength of $1100 \mathrm{MPa}$, which is better than the fibers with the strength of $2000 \mathrm{MPa}$, mainly due to their high $\mathrm{L} / \mathrm{D}$ ratio. Among the six fibers, compared with the reference beam $\mathrm{S}$, the bending moment of the B3 and L3 beams decreased 1.63\% and 3.38\%, respectively, because the tensile strength of the two fibers was small, $590 \mathrm{MPa}$, the $\mathrm{L} / \mathrm{D}$ ratio is also small, and brittleness is larger, the incorporation of concrete after the increase of internal defects, their own tensile strength is less than fiber and concrete interface bonding force.

From Fig. 6(b), it can be seen that, with the exception of the B3 and L3 beams, the other beams' cross-deflection has increased with the fiber into the beam in the yield state, because with the load increases, the cracks continue to expand, the steel fiber will be separated from the concrete matrix before fracture, resulting in a sudden increase in beam deformation. Among the beams B1, B2, D1 and D2, the increase of the span deflection of the beams D2 and D1 are larger than that of the base beam $\mathrm{S}$, which respectively are $2.82 \%$ and $2.01 \%$, while the midspan deflection of the corrugated fiber beams B1 and B2 are increased by $1.48 \%$ and $0.78 \%$, respectively compared with the $\mathrm{S}$. This is because the end hook fiber can bond with the cement matrix better, and the bond between the fiber and concrete is large, which can carry larger load. When the fiber pulled out from the matrix, the beam deformation is also generated will be greater. The deflection of $\mathrm{B} 3$ and L3 beams is reduced by $6 \%$ compared with $\mathrm{S}$, which is mainly due to the brittleness of B3 and L3 fibers, so the internal defects of concrete are increased. When the load is near the yield state, the tensile strength of the fiber itself is less than the interfacial bonding force, so that it can not be fully exerted, on the contrary the bearing capacity of the fiber beam is weakened.

\subsubsection{Cloud of equivalent yield}

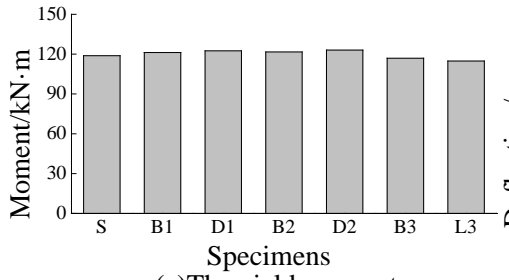

(a)The yield moment

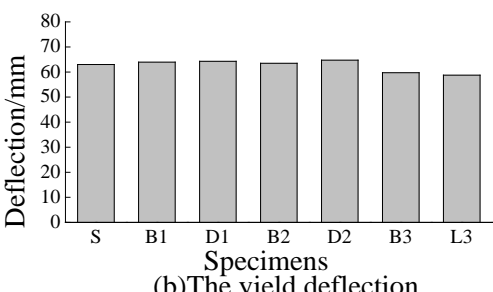

(b)The yield deflection

Fig. 6 The yield moment anddeflection of UHPC beams

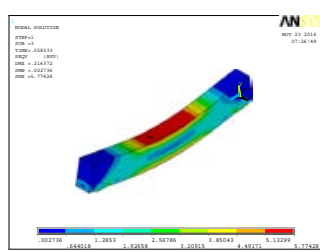

(a) $S$

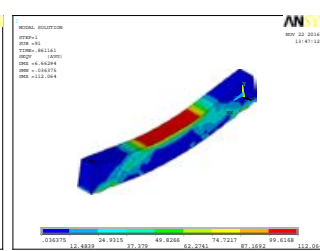

(b)B1

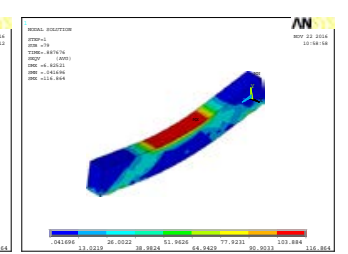

(c)D1

stress.

Fig. 7 shows the equivalent yield stress plots of UHPC beams. It can be seen that the maximum

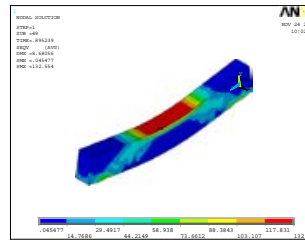

(d)B2

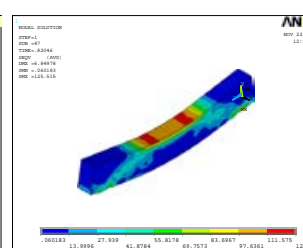

(e)D2

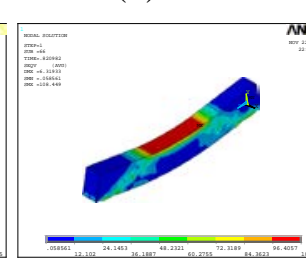

(f)B3

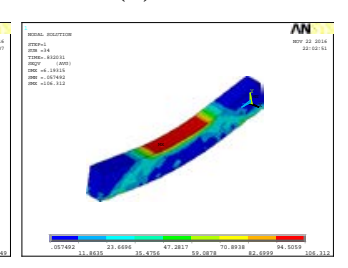

(g)L3

Fig. 7 The Equivalent cracking von Mises stress of UHPC beam 
compressive stress in the beam during the yield stage of the beam occurs in the upper compression zone due to that the stress of concrete in compression area suddenly increased rapidly after the steel bar yielded. Compared with S, the maximum yield stress of D2 beam are increased by $12 \%$, which is the most obvious among six kinds of fiber beams. The maximum yield stress of D1, B1 and B2 beam are increased by $4.28 \% 2.52 \%$ and $2.46 \%$. The increase of the maximum yield stress of the beam is mainly due to the cohesive force between the steel fiber and the concrete makes them one to bear the load together. When load increase step by step untill the beam reaches the yield state, the steel fiber will need to consume more energy so that steel fiber with concrete matrix separation and even be broken, and the integrity between hook-type fiber and concrete is better. Compared with S, the maximum yield stress of L3, B3 are decreased by 5.13\%, 3.23\%. The reason is that B3, L3 fibers have relatively small diameters and low strength, and the workability of concrete decreases due to the incorporation of fiber, resulting in micro-cracks in concrete and that the flexural capacity of beams is lower than the fiber-free.

\section{Ultimate flexural capacity formula of UHPC beam}

\subsection{Derivation of ultimate flexural capacity formula.}

When the concrete beam is mixed with silica fume, the beam has high tensile strength. When the bearing capacity of the beam is calculated, it is necessary to consider the effect of silica fume on the tensile strength of the beam. The formula of the ultimate bearing capacity of the beam is deduced based on the formula of the ultimate bearing capacity of the high-strength concrete beam. In this paper, Wang Zhao-ning et al ${ }^{[10]}$ the ultimate bearing capacity formula as the basic formula:

$$
\begin{gathered}
M_{u}=f_{c m} b x\left(h_{0}-\frac{x}{2}\right)-f_{t b} b x_{t}\left(\frac{x_{t}}{2}-a_{s}\right) \\
x=\frac{A_{s} f_{y}+f_{t b} b h}{b\left(f_{c m}+1.54 f_{t b}\right)}
\end{gathered}
$$

Where $M_{u}$ is design value of flexural bearing capacity of concrete beams, $f_{c m}$ is design value of compressive strength of concrete, $f_{c m}=0.85 f_{c} ; f_{t b}$ is design value of tensile strength of concrete; $f_{y}$ is sectional area of longitudinal reinforcement bar; $a_{s}$ is thickness of protective layer in tension zone; $x, x_{t}$ respectively are the height of pressure zone and tension zone, $x_{t}=h_{0}-x$;

Considering the reinforcing effect of steel fiber on the normal section of high-strength concrete beam, we modify equation (6)

$$
M_{f u}=\left(1+\beta_{f}\right) M_{u}
$$

Where $M_{f u}$ is design value of flexural bearing capacity of ultra-high performance concrete members; $\beta_{f}$ is correction coefficient of steel fiber, related to content eigenvalues of steel fiber $\lambda_{f}=\rho_{f} l_{f} / d_{f}$ and tensile strength of steel fiber $f_{f y}$;

The relationship between content eigenvalues of steel fiber $\lambda_{f}$ and tensile strength of steel fiber $f_{f y}$ with correction coefficient of steel fiber $\beta_{f}$ for non-linear statistical regression is obtained:

$$
\beta_{f}=-0.1131-0.2125 \lambda_{f}+0.38 \times 10^{-3} f_{f y}+0.0894 \lambda_{f}^{2}-1.28 \times 10^{-7} f_{f y}^{2}
$$

After plugging pertinent data of test beam into equation (8) (9), we can calculate the ultimate bearing capacity of normal section of the corresponding beam.

\subsection{Comparison between the calculated value and analog value.}

Fig.8 is comparison dot of calculated value and analog value of UHPC beams. The result of the ultimate capacity calculated by equations (8) (9) are as follows: the mean value is 0.973 ; the standard deviation is 0.0037 ; and the coefficient of variation is 0.0038. It follows that the calculation method of ultimate bearing capacity is basically available. And the calculated values are generally lower than the analog value, which means that the ultimate bearing capacity calculated by equations (8) (9) is relatively safe for structure.

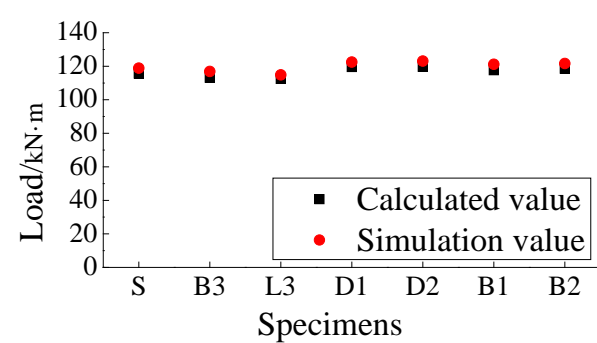

Fig. 8 the calculated value and the simulation value of ultimate bearing capacity 


\section{Conclusion}

In this paper, through finite element simulation analysis, the results of the study on the effect of different type steel fiber on UHPC beams' cracking load and ultimate load show that:

(1) The incorporation of steel fiber have little influence on compressive strength of beams, but it does the opposite on tensile strength. The incorporation of steel fiber limited the crack development and enhanced the toughness of the beam. The cracking load and yield load of the beams increased with the increase of $\mathrm{L} / \mathrm{D}$ ratio.

(2) When the fiber with the same strength was incorporated, the end-hook fiber had the most obvious reinforcing effect, while the bearing capacity of the screw-type fiber beam was lower than that of the plain concrete.

(3) When the fiber with the same shape was incorporated, the bending strength of the beam which was incorporated into steel fiber D1 or D2 with the tensile strength of $2000 \mathrm{MPa}$ was enhanced most obviously. The ultimate bearing capacity of the steel fiber was increased by 3\% 4\%. Mixed with B3 or L3 steel fiber whose tensile strength is $590 \mathrm{MPa}$, the bending capacity of the beams are inferior to reference beam $\mathrm{S}$ caused by its brittleness.

(4) Based on the formula of flexural capacity of high-strength concrete beams, the formulas of ultimate flexural capacity for UHPC beams are obtained, and the calculated values of ultimate bearing capacity are in accordance with the simulated values.

\section{References}

[1] AFGC. Ultra High Performance Fibre-Reinforced Concerte-Recommendations. Revised Edition. June 2013.

[2] Lin Xiaosong, Cao Guo'e, steel fiber shape on the high-strength concrete to enhance the impact of [J]. Journal of Xiangtan University, 2002 17(3): 63-66.

[3] Cao Xiaoxia, Zheng Juhuan. Effect of steel fiber and polypropylene crude fiber on strength and ductility of reactive powder concrete [J]. Journal of Anhui Institute of Architecture \& Industry. 2011, 19(2): 58-61.

[4] Giuseppe Tiberti, Fausto Minelli, Giovanni A, Plizzari. Influence of concrete strength on crack development in SFRC members [J]. Cement\&Concrete Composites. 2014(45): 176-185.

[5] Jacek Katze, Jacek Domski. Quality and mechanical properties of engineered steel fibers used as reinforcement for concrete [J]. Construction and Building Materials. 2012(34): 243-248.

[6] Yang Jiujun, Liu Junxia, Han Jingyi. Study on mechanical properties of ultra-high strength steel fiber reinforced concrete with high fluidity [J]. Journal of Building Materials. 2010, 13(1): 1-6.

[7] Du Xiuli, Tian Yudong, Dou Guoqin. Preparation and Mechanical Properties of Fiber Super-high-strength Concrete [J]. 2011(2): 44-49.

[8] Serkan Tokgoz, a, Cengiz Dudar. Experimental behavior of steel fiber high strength reinforced concrete and composite columns [J]. Journal of Constructional Steel Research. 2012(74): 98-107.

[9] Liu Yongsheng, Wang Xiaojun, Jin Ting, Lao Jun. Study on Mechanical Properties and Constitutive Relation of Steel Fiber Reinforced Concrete [J]. Journal of University of Science and Technology of China. 2007(07): 717-723.

[10] Wang Zhaoning. Reactive powder concrete rectangular section of reinforced beam flexural performance research [D]. Beijing Jiaotong University. 2008. 